\title{
Evaluation of Weight Gain and Metabolic Parameters among Adolescent Psychiatric Inpatients: Role of Health Promotion and Life Style Intervention Programs
}

\author{
Valsamma Eapen ${ }^{1,3 *}$, Gerard Faure-Brac ${ }^{2}$, Philip B. Ward ${ }^{3,7}$, Philip Hazell ${ }^{4}$, Giles Barton ${ }^{5}$, Mona Asghari-Fard ${ }^{1}$ and Pravin Dullur ${ }^{6}$ \\ ${ }^{1}$ Academic unit of Child Psychiatry South West Sydney (AUCS), ICAMHS-Mental Health Centre, Liverpool Hospital, Liverpool, NSW, Australia \\ 'Sydney Local Health District, Missenden Road, NSW, Australia \\ ${ }^{3}$ School of Psychiatry, University of New South Wales (UNSW), Sydney, Australia \\ ${ }^{4}$ Discipline of Psychiatry, University of Sydney, Australia \\ ${ }^{5}$ ICAMHS, Liverpool, NSW, Australia \\ ${ }^{6}$ Gna Ka Lun Adolescent Mental Health Unit, Campbelltown Hospital, Campbelltown, NSW, Australia \\ ${ }^{7}$ Schizophnenia Research Unit, South Western Sydney Local Health District, Australia
}

\begin{abstract}
Objective: The purpose of the current preliminary study was to estimate the nature and occurrence of metabolic abnormalities among adolescent inpatients receiving psychiatric treatment and to pilot a health promotion and life style intervention program.
\end{abstract}

Method: A total of 107 adolescents admitted over a 12-month period were evaluated for physical, clinical and metabolic parameters in two inpatient psychiatric units in Sydney, Australia, where a health promotion and life style intervention program was provided under the leadership of a Sports Psychologist.

Results: $46 \%$ of subjects were found to be "at risk for adverse health outcome" with one or more metabolic abnormalities and $4.6 \%$ qualified for a diagnosis of Metabolic Syndrome meeting 3 or more of the modified criteria for Metabolic Syndrome in young people. 13\% of the sample was overweight with abnormal Body Mass Index (BMI). While two thirds recognized the importance of staying physically active, only a quarter were maintaining adequate level of physical activity. Regarding quality of life, only 30 to $40 \%$ reported good life and health satisfaction.

Conclusion: Our findings suggest that metabolic abnormalities are not uncommon among young psychiatric patients and that they are often missed. Regular monitoring for the presence of metabolic abnormalities and clinical risk factors should be part of the comprehensive management with special focus on preventative programs.

Keywords: Adolescents; Second generation antipsychotics; Metabolic syndrome; Health promotion; Life style intervention

\section{Introduction}

Young people with psychotic disorders and other psychiatric conditions necessitate treatment with antipsychotic medication $[1,2]$ and prescription of Second Generation Antipsychotics (SGAs) has increased substantially among young patients [3]. However, up to $80 \%$ of patients treated with SGAs experience significant weight gain as a side effect of these medications [4]. Further, evidence suggests that the weight gain and related side effects of SGAs are greater in the young population than in adults $[5,6]$. In addition to the personal distress this causes to patients and their families, there are significant medical problems linked to such weight gain, including increased risk of type 2 diabetes, cardioascular morbidity and Metabolic Syndrome (MS) [7].

Childhood obesity is reaching epidemic proportions worldwide and the adverse medical effects of obesity including MS and type 2 diabetes represent a serious public health concern $[8,9]$. Weight gain and obesity related complications account for some of the excess morbidity and mortality in patients with mental illness [10]. As these young people are simultaneously affected by the emotional distress and social impairment linked to their mental illness, specific, targeted interventions need to be developed and evaluated for this vulnerable population. Recent studies have also suggested the role of genetic factors in determining who is most likely to experience weight gain linked to taking anti-psychotic medication.

Available evidence from the literature suggests that childhood obesity tracks into adulthood [11] and that they are at risk for obesity related complications including dyslipidemia, atheroma, insulin resistance, systemic inflammation and oxidative stress [12]. Although direct comparison across studies is difficult due to differences in the definition of the syndrome, it is estimated that 3 to $4 \%$ of adolescents have MS [13]. This risk is believed to be even greater for mentally ill young patients taking SGAs [14], which could interfere with their treatment adherence and recovery. Studies that have compared the effect of different SGAs on weight gain, obesity-related complications, and metabolic side effects in the young population [15-18] have highlighted the importance of monitoring for metabolic effects of SGAs in children and adolescents. Walter et al. [19] using a survey of Child Psychiatrists in Australia observed that, while concern regarding weight gain and metabolic side effects was high, the monitoring practices did not correspond to these concerns. In this regard Ellis et al. [20] described a novel program to facilitate monitoring of physical health and side effects in young patients treated with SGA. Furthermore, specialised treatment services for young patients have developed pilot programs for monitoring physical health status in first episode psychosis [21-22].

While weight gain and metabolic change induced by SGAs is

*Corresponding author: Valsamma Eapen, MBBS, PhD, FRCPsych, FRANZCP, Academic unit of Child Psychiatry South West Sydney (AUCS), ICAMHS, Menta Health Centre, L1, Liverpool Hospital, Elizabeth Street, Liverpool, NSW 2170, Australia, Tel: (+61) -2-96164245; Fax: (+61) -2-96012773; E-mail: v.eapen@unsw.edu.au

Received March 16, 2012; Accepted April 20, 2012; Published April 25, 2012

Citation: Eapen V, Brac GF, Ward P, Hazell P, Barton G, et al. (2012) Evaluation of Weight Gain and Metabolic Parameters among Adolescent Psychiatric Inpatients: Role of Health Promotion and Life Style Intervention Programs. J Metabol Syndro 1:109. doi:10.4172/2167-0943.1000109

Copyright: (c) 2012 Eapen V. This is an open-access article distributed under the terms of the Creative Commons Attribution License, which permits unrestricted use, distribution, and reproduction in any medium, provided the original author and source are credited. 
Citation: Eapen V, Brac GF, Ward P, Hazell P, Barton G, et al. (2012) Evaluation of Weight Gain and Metabolic Parameters among Adolescent Psychiatric Inpatients: Role of Health Promotion and Life Style Intervention Programs. J Metabol Syndro 1:109. doi:10.4172/21670943.1000109

Page 2 of 4

\begin{tabular}{|c|c|c|c|}
\hline & & $\begin{array}{l}\text { One or more Cook et } \\
\text { al. [25] criteria positive }\end{array}$ & $P$ Value \\
\hline Total: & 107 & & \\
\hline \multicolumn{4}{|l|}{ Sex: } \\
\hline Female & $73.9 \%$ & $49.3 \%(37 / 75)$ & 0.224 \\
\hline Male & $26.1 \%$ & $63 \%(17 / 27)$ & \\
\hline \multicolumn{4}{|l|}{ Age: } \\
\hline $10-12$ & $3.7 \%$ & $50 \%(2 / 4)$ & 0.065 \\
\hline $13-15$ & $41 \%$ & $63.7 \%(28 / 44)$ & \\
\hline $16-18$ & $55 \%$ & $52.5 \%(28 / 59)$ & \\
\hline \multicolumn{4}{|l|}{ Ethnicity of Mother: } \\
\hline White/Australian & $66 \%$ & $39.4 \%$ & 0.177 \\
\hline Others & & $14.1 \%$ & \\
\hline \multicolumn{4}{|l|}{ Ethnicity of Father: } \\
\hline White/Australian & $66 \%$ & $40 \%$ & 0.549 \\
\hline \multicolumn{4}{|l|}{ Others } \\
\hline Subjects Medical History: & $19 \%$ & $14.7 \%$ & 119 \\
\hline \multicolumn{4}{|l|}{ Yes } \\
\hline \multicolumn{4}{|c|}{ On medication for Mental illness: } \\
\hline Yes & $71 \%$ & $70.3 \%$ & 0.500 \\
\hline On SGA & $49.5 \%$ & $54 \%$ & \\
\hline Other medication & $21.5 \%$ & $34 \%$ & \\
\hline \multicolumn{4}{|l|}{ Family History of diabetes: } \\
\hline Yes & $18 \%$ & $58.8 \%$ & 0.643 \\
\hline \multicolumn{4}{|c|}{ Family History of Hypertension: } \\
\hline Yes & $20.2 \%$ & $61 \%$ & 0.624 \\
\hline \multicolumn{4}{|l|}{ Family History of obesity: } \\
\hline Yes & $19.4 \%$ & $38.9 \%$ & 0.108 \\
\hline \multicolumn{4}{|l|}{ Living with: } \\
\hline Both Parents & $42.1 \%$ & $46 \%$ & \\
\hline Single parent & $40 \%$ & $61 \%$ & \\
\hline Parents plus partner & $10 \%$ & $50 \%$ & \\
\hline Others & $5 \%$ & $20 \%$ & \\
\hline Institution & $3 \%$ & $100 \%$ & \\
\hline
\end{tabular}

gender and Body Mass Index (BMI) was calculated using body mass index-for age percentiles based on gender as per the CDC criteria [9]. Metabolic parameters were obtained such as fasting blood sugar level, High Density Lipoprotein (HDL) cholesterol levels and Triglyceride (TG) levels. Data was collated and checked against the criteria for being "at risk for adverse health outcome" according to Correll et al. criteria [24] and for features of MS as per the National Cholesterol Education program's Adult Treatment Panel III Criteria modified by Cook for use in young people [25].

Along with the evaluation of the clincial and metabolic profile, the patients also completed questionnaires designed to ascertain their Quality of Life using World Health Organization Quality of Life (WHOQOL) as well as their current attitudes and level of physical activity. Participants rated their level of physical activity, their confidence in overcoming things that can get in the way of doing regular physical activity, their belief about the importance and pros and cons of carrying out physical activity on a regular basis as well as their use of strategies to improve their level of activity. Physical activity change strategies were also ascertained and participants reported on their use of strategies to improve the level of physical activity such as obtaining information, putting reminders, changing the environment, keeping track of activity levels etc.

As part of the in-patient management, the patients participated in a Health Promotion and Lifestyle Intervention program run under the leadership of a Sports Psychologist. The program consisted of individual and group activities and the key components of the program were 1) Focus on Physical health and creative arts 2) Education and Dietary counselling 3) Psychological support. The Physical Health component focussed on Exercise group, Sports group, Gym and Adventure activities. The education component used discussion groups and provision of information on diet, exercise and healthy living. Psychological intervention included group sessions and individual counselling using motivational interviewing aimed at changing attitudes and beliefs to promote healthy lifestyle.

The association between sociodemographic factors (e.g. age, gender, ethnicity), personal factors (e.g. family background, family history), and clinical factors (e.g. diagnosis, treatment received) on weight gain and metabolic changes were ealuated using Chi square tests and significance levels were set at $\mathrm{p}<0.01$.

\section{Results}

Of the 107 patients admitted to the unit during the period of study, 73 were females. There were no significant differences in demographic characteristics between those with metabolic abnormalities and those without (Table 1). Seventy one percent were on medication for their mental illness, of which $50 \%$ were on SGAs at the time of evaluation. The duration of exposure to SGAs varied from two weeks to 6 months. Two out of the four subjects (50\%) in the 10-12 age group, 28 out of the $44(63.7 \%)$ in the $13-15$ age groups and 28 out of the $59(52.5 \%)$ in the 16-18 age group were found to be positive for one or more metabolic abnormalities. Based on the Correll criteria, $53 \%$ of subjects had 1 or more risk factors for Adverse Health Outcome. Table 2 describes the nature and occurrence of the metabolic abnormalities in the sample as per Cook criteria. $13.9 \%$ of the subjects were categorised as overweight; $35.2 \%$ were positive for hypertension; $22 \%$ were positive for high TG; $10.8 \%$ had abnormal HDL and 3\% were positive for high blood sugar. Metabolic abnormalities were more common in males with $63 \%$ being positive for one or more of the metabolic abnormalities. $4.6 \%$ of the study population were positive for 3 or more criteria for metabolic syndrome as per Cook criteria, thus qualifying for a diagnosis of MS. 
Citation: Eapen V, Brac GF, Ward P, Hazell P, Barton G, et al. (2012) Evaluation of Weight Gain and Metabolic Parameters among Adolescent Psychiatric Inpatients: Role of Health Promotion and Life Style Intervention Programs. J Metabol Syndro 1:109. doi:10.4172/21670943.1000109

Page 3 of 4

\begin{tabular}{|l|c|}
\hline \multicolumn{1}{|c|}{ Metabolic abnormality } & Cook Criteria Positive \\
\hline Body Mass Index (BMI) & $13.9 \%$ \\
\hline Blood Pressure & $35.2 \%$ \\
\hline Triglycerides & $22 \%$ \\
\hline High Density Lipoprotein (HDL) & $10.8 \%$ \\
\hline Blood Glucose & $3 \%$ \\
\hline MS diagnosis ( $\geq$ three criteria positive): & $4.6 \%$ \\
\hline Three criteria positive & $3.7 \%$ \\
\hline Four criteria positive & $0.9 \%$ \\
\hline
\end{tabular}

Table 2: Occurrence of metabolic abnormalities in the sample.

None of these metabolic abnormalities had been detected prior to the screening carried out as part of this project.

There was no association between being on SGAs and having MS $\left(\mathrm{X}^{2}=1.387 ; \mathrm{p}=0.500\right)$. With regard to living arrangements, all three of those living in institutional setting were positive for one or more metabolic abnormalities. There was no association between having a metabolic abnormality in the patient and family history of diabetes $\left(\left(\mathrm{X}^{2}=0.884 ; \mathrm{p}=0.643\right)\right.$; family history of obesity $\left(\mathrm{X}^{2}=4.450 ; \mathrm{p}=0.108\right)$ and family history of hypertension $\left.\left(\mathrm{X}^{2}=0.944 ; \mathrm{p}=0.642\right)\right)$.

With regards to the current level of physical activity, $19.7 \%$ reported doing physical activity for 60 minutes or more per day on 5 or more days of the week, while the percentage of young people who reported carrying out the same level of activity on 4, 3, 2, and 1 day per week were $9.8 \%, 18 \%, 14.8 \%$, and $19.7 \%$ respectively (mean $=3.5$; Standard Deviation $=1.9$ ). Regarding future plans, $32.8 \%$ reported that in the next 6 months they intend to start doing 60 minutes or more of physical activity per day on 5 days or more per week. When asked about their attitudes and belief about how important physical activity was for them, $32 \%$ reported that they considered it as not important while $29 \%$ reported it was either moderately or extremely important. The pros and cons were rated on items such as "it will keep me fit", or "it will take time away from friends". There was no significant association between gender $\left(\mathrm{X}^{2}=5.432 ; \mathrm{p}=0.245\right)$, $\mathrm{BMI}\left(\mathrm{X}^{2}=4.11 ; \mathrm{p}=0.391\right)$, or metabolic abnormalities $\left(\mathrm{X}^{2}=4.495 ; \mathrm{p}=0.343\right)$, and the level of importance given to physical activity. On the physical activity confidence scale, the participants reported their confidence in being able to overcome things that can get in the way of doing physical activity such as setting aside time, being able to do it despite bad weather or during times of school projects etc. $30 \%$ reported that they do not feel confident that they can overcome such challenges, $30 \%$ reported that they feel confident that they can and the remaining $40 \%$ gave a neutral response. Again no significant associations were noted between the confidence level and gender $\left(\mathrm{X}^{2}=534 ; \mathrm{p}=0.766\right.$. $)$, BMI $\left(\mathrm{X}^{2}=1.156 ; \mathrm{p}=0.561\right)$, or metabolic abnormalities $\left(\mathrm{X}^{2}=2.842 ; \mathrm{p}=0.242\right)$. While $32.5 \%$ reported that they never used physical activity change strategies that would help them to improve the level of activity, 35.5\% reported using these sometimes and 32\% as often. There was no significant association between the use of physical activity change strategies and gender $\left(\mathrm{X}^{2}=2.743 ; \mathrm{p}=0.254\right), \mathrm{BMI}\left(\mathrm{X}^{2}=0.685 ; \mathrm{p}=0.710\right)$, or metabolic abnormalities $\left(\mathrm{X}^{2}=2.086 .352 ; \mathrm{p}=0.352\right)$.

On the WHO-QOL, life satisfaction was reported as poor by $33 \%$, average by $37.5 \%$ and good by $29.5 \%$. Regarding health satisfaction, $39.5 \%$ each reported this to be poor or good while $21 \%$ reported average level of satisfaction.

\section{Discussion}

Our findings of at least one risk factor for adverse health outcome in $46 \%$ and MS in $4.6 \%$ highlight the importance of routine metabolic monitoring in adolescent psychiatric population. The rates were found to be higher in males and in the younger age group. The finding of no association between exposure to SGAs and metabolic abnormalities coupled with the observation that $60 \%$ of our sample had been on SGAs for less than 6 months seem to suggest that those with mental illness per se are at increased risk of metabolic abnormalities, perhaps due to poor dietary habits, sedentary and unhealthy lifestyle maintained by the mentally ill. In this regard, Psychiatrists and primary care providers must be aware that, risk factors for psychiatric and metabolic disorders may cluster in young people just as it occurs in adults. Early identification of weight gain along with physical, clinical and metabolic abnormalities should take priority in the young mentally ill patients. In these situations, special attention should be given to the quantification of weight gain and obesity, as well as focus on life style intervention addressing diets and dietary patterns, physical activity, awareness and attitudes about healthy living. Emotional issues including anxiety and depression, as well as motivation for change should be addressed along with provision of appropriate psychological support and intervention. Techniques including motivational interviewing and health promotion strategies such as altering poor dietary habits and sedentary life style should be an integral part of management in these patients. Attention to psychological issues should also be a priority with promotion of stress management and better coping strategies as body image and self esteem are important to the adolescent population and low self esteem has been found to correlate with lack of motivation to be physically active [26]. The latter being a critical component of the modifiable variable in the management of obesity, instilling self worth and positive self perception in young people should be part of the comprehensive management of this vulnerable population [27].

Regarding management, a number of cognitive behavioural strategies have been found to be effective in helping individuals make lifestyle changes thus promoting patient satisfaction and physical well being [28-29]. Given the adverse effect of weight gain on compliance and relapse rates [30], as well as on social stigma and discrimination [31], evaluating the potential beneficial effects of preventative programs is of immense clinical importance. If not, physical changes due to weight gain may lead to poor body image and self-esteem and also result in non-adherence to treatment regimes. A recent systematic review and meta-analysis of randomised controlled trials of nonpharmacological management of antipsychotic induced weight gain in the adult population found that adjunctive non-pharmacological interventions were effective in attenuating antipsychotic-induced weight gain compared with treatment as usual, with treatment effects maintained over follow up [32]. We believe that the components of the health promotion program outlined here have several advantages especially for the newly diagnosed. It is hoped that introduction of such programs in routine clinical practice would prevent weight gain, improve compliance and overall well being and quality of life in children and adolescents with mental illness.

\section{Limitations}

While the current study achieved the aim of ascertaining the occurrence of metabolic abnormalities among adolescent psychiatric inpatients, due to the small sample size and the relatively short and variable duration of exposure to SGAs, it was not possible to determine any potential link between a particular drug and the occurrence of metabolic abnormalities. It is to be noted that around $60 \%$ of adolescents in this study were on second generation antipsychotic medication for less than 6 months and therefore the association between the two cannot be concluded. Further studies should clarify this by following up subjects from baseline prior to initiation of medication and then at regular intervals. Not withstanding the fact that the data is limited due to the cross sectional nature of the assessment and intervention 
Citation: Eapen V, Brac GF, Ward P, Hazell P, Barton G, et al. (2012) Evaluation of Weight Gain and Metabolic Parameters among Adolescent Psychiatric Inpatients: Role of Health Promotion and Life Style Intervention Programs. J Metabol Syndro 1:109. doi:10.4172/21670943.1000109

program provided during their inpatient stay, this pilot study clarified beyond doubt the need for regular monitoring for physical health and metabolic parameters. Similarly, while the feasibility of including preventative programs as an integral part of the comprehensive inpateint management was established, follow up data is critical in evaluating the long term benefits of the program.

\section{Conclusion}

Our findings suggest that around half of adolescent patients receiving inpatient treatment for mental illness have one or more physical or metabolic abnormalities. However without routine monitoring they go unrecognized and are at risk for future adverse health outcomes. Given the clinical staging model where treatment effects are thought to be the greatest when provided early, preventive strategies would be most effective if these young people are targeted as early as possible. In this regard a recent systematic review highlighted the need for close screening and monitoring of metabolic side effects in young patients exposed to antipsychotics and good collaboration between child and adolescent psychiatrists, General Practitioners and Paediatricians to achieve this [33].

\section{Acknowledgment}

This study was supported by a grant from the Australian Rotary Health Research Fund for evaluation of Mental Health Service Provision (RG084844). The authors would like to acknowledge the contributions of Dr Rosemary Anderson, Staff Specialist at Rivendell, Dr Tania Trapolini, research Officer at Liverpoo Hospital, Kirsten Moss and Mary Bouton who worked as Research Assistants on this project as well as all staff and patients at Rivendell and Gna Ka Lun Adolescent units who participated in this study.

\section{References}

1. Armenteros JL, Davies M (2006) Antipsychotics in early onset schizophrenia: systematic review and meta-analysis. Eur Child Adolesc Psychiatry 15: 141148

2. Olfson M, Marcus SC, Weissman MM, Jensen PS (2002) National trends in the use of psychotropic medications by children. J Am Acad Child Adolesc Psychiatry 41: 514-521.

3. Patel NC Crismon ML, Hoagwood K, Johnsrud MT, Rascati KL, et al. (2005) Trends in the use of typical and atypical antipsychotics in children and adolescents. J Am Acad Child Adolesc Psychiatry 44: 548-556.

4. Green Al, Patel JK, Goisman RM, Allison DB, Blackburn G (2000) Weight gain from novel antipsychotic drugs: need for action. Gen Hosp Psychiatry 22: 224 235.

5. Ratzoni G, Gothelf D, Brand-Gothelf A, Reidman J, Kikinzon L, et al. (2002) Weight gain associated with olanzapine and risperidone in adolescent patients: a comparative prospective study. J Am Acad Child Adolesc Psychiatry 41: 337 343.

6. Sikich L, Hamer RM, Bashford RA, Sheitman BB, Lieberman JA (2004) A pilo study of risperidone, olanzapine, and haloperidol in psychotic youth: a doubleblind randomized, 8-week trial. Neuropsychopharmacology 29: 133-145.

7. Correll CU, Carlson HE (2006) Endocrine and metabolic adverse effects of pychotropic medications in children and adolescents. J Am Acad Child and Adolesc Psychiatry 45:771-791.

8. World Health Organisation. Controlling the global obesity epidemic.

9. Centres for Disease Control and prevention. Data Table of BMI for age charts.

10. Cohn TA, Sernyak MJ (2006) Metabolic monitoring for patients treated with antipsychotic medications. Can J Psychiatry 51: 492-501.

11. Magarey AM, Daniels LA, Boulton TJ, Cockington RA (2003) Predicting obesity in early adulthood from childhood and parental obesity. Int J Obes Relat metab Disord 27: 505-513.

12. Burke V (2006) Obesity in childhood and cardiovascular risk. Clin Exp Pharmacol Physiol 33: 831-837.

13. Cruz ML, Goran MI (2004) The metabolic syndrome in children and adolescents. Curr Diab Rep 4: 53-62.
14. Alvarez-Jiménez M, González-Blanch C, Crespo-Facorro B, Hetrick S, Rodríguez-Sánchez JM, et al. (2008) Antipsychotic-induced weight gain in chronic and first-episode psychotic disorders: a systematic critical reappraisal. CNS Drugs 22: 547-562.

15. Curtis J, Henry C, Watkins A, Newall H, Samaras K, et al. (2011) Metabolic abnormalities in an early psychosis service: a retrospective, naturalistic crosssectional study. Early Interv Psychaitry 5: 108-114.

16. Fleischhaker C, Heiser P, Hennighausen K, Herpertz-Dahlmann B, Holtkamp $\mathrm{K}$, et al. (2006) Clinical drug monitoring in child and adolescent psychiatry: side effects of atypical neuroleptics. J Child Adolesc Psychopharmacol 16: 308-316.

17. Fleischhaker C, Heiser P, Hennighausen K, Herpertz-Dahlmann B, Holtkamp K et al. (2007) Weight gain associated with clozapine, olanzapine and risperidone in children and adolescents. J Neural Transm 114: 273-280.

18. Fraguas D, Merchán-Naranjo J, Laita P, Parellada M, Moreno D, et al. (2008) Metabolic and hormonal side effects in children and adolescents treated with second-generation antipsychotics. J Clin Psychiatry 69: 1166-1175.

19. Walter G, DeLaroche A, Soh N, Hunt G, Cleary M, et al. (2008) Side effects of second-generation antipsychotics: the experiences, views and monitoring practices of Australian child psychiatrists. Australas Psychiatry 16: 253-262.

20. Ellis D, Shirzadi K, Grzeskowiak L, Angley M (2008) Development of a nove program to facilitate monitoring physical health and adverse effects in children and adolescents prescribed antipsychotic medication. Australas Psychiatry 16 368-369.

21. Mitchell AJ, Delaffon V, Vancampfort D, Correll CU, De Hert M (2012) Guideline concordant monitoring of metabolic risk in people treated with antipsychotic medication: systematic review and meta-analysis of screening practices. Psychol Med 42: 125-147.

22. Hetrick S, Alvarez-Jiménez M, Parker A, Hughes F, Willet M, et al. (2010) Promoting physical health in youth mental health services: ensuring routine monitoring of weight and metabolic indices in a first episode psychosis clinic. Australas Psychiatry 18: 451-455.

23. Correll CU, Manu P, Olshanskiy V, Napolitano B, Kane JM, et al. (2009) Cardiometabolic risk of second-generation antipsychotic medications during first-time use in children and adolescents. JAMA 302: 1765-1773.

24. Correll CU, Penzner JB, Patrik UH, Mughal T, Javed T, et al. (2006) Recognizing and monitoring adverse events of second generation antipsychotics in children and adolescents. Child Adolesc Psychiatr Clin N Am 15: 177-206.

25. Cook S, Weitzman M, Auinger P, Nguyen M, Dietz WH (2003) Prevalence of a metabolic syndrome phenotype in adolescents: findings from the Third National Health and Nutrition Examination survey, 1988-1994. Arch Pediatr Adolesc Med 157: 821-827.

26. Biddle SJ, Mutrie N (2001) Psychology of physical activity: Determinants, wellbeing, and interventions, Routledge, London.

27. Eapen V, John G (2011) Weight gain and metabolic syndrome among young patients on antipsychotic medication: what do we know and where do we go? Australas Psychiatry 19: 232-235.

28. Brar JS, Ganguli R, Pandina G, Turkoz I, Berry S, et al. (2005) Effects of behavioural therapy on weight loss in overweight and obese patients with schizophrenia or schizoaffective disorder. J Clin Psychiatry 66: 205-212.

29. Kwon JS, Choi JS, Bahk WM, Yoon Kim C, Hyung Kim C, et al. (2006) Weight management program for treatment-emergent weight gain in olanzapinetreated patients with schizophrenia or schizoaffective disorder. A 12-week randomized controlled clinical trial. J Clin Psychiatry 67: 547-553.

30. Allison DB, Mackell JA, McDonnell DD (2003) The impact of weight gain on quality of life among persons with schizophrenia. Psychiatr Serv 54: 565-567.

31. Aronne LJ (2001) Epidemiology, morbidity, and treatment of overweight and obesity. J Clin Psychiatry 62: 13-22.

32. Alvarez-Jiménez M, Hetrick SE, González-Blanch C, Gleeson JF, McGorry PD (2008) Non-pharmacological management of antipsychotic-induced weight gain: systematic review and meta-analysis of randomised controlled trials. $\mathrm{Br} \mathrm{J}$ Psychiatry 193: 101-107.

33. De Hert M, Dobbelaere M, Sheridan EM, Cohen D, Correll CU (2011) Metabolic and endocrine adverse effects of second-generation antipsychotics in children and adolescents: A systematic review of randomized, placebo controlled trials and guidelines for clinical practice. Eur Psychiatry 26: 144-158. 